\title{
Time-dependent inhibition of insulin release: suppression of the arginine effect by hyperglycaemia
}

\author{
R. Nesher, B. Tuch, C. Hage, J. Levy and E.Cerasi \\ Department of Endocrinology and Metabolism, The Hebrew University Hadassah Medical Center, Jerusalem, Israel
}

\begin{abstract}
Summary. Brief stimulation of the pancreas with arginine causes a refractory state which reduces the insulin response to subsequent stimulations (time-dependent inhibition). In control subjects, a pair of arginine injections $(75 \mathrm{mg} / \mathrm{kg}$ ) at a 30 -min interval resulted in $20 \%$ reduction of peak and integrated insulin responses to the second injection. In Type 2 (non-insulin-dependent) diabetic patients and in obese subjects, the inhibitory effect of repeated arginine stimuli was abolished. Healthy subjects were made acutely hyperglycaemic $(9.3 \pm 0.3 \mathrm{mmol} / \mathrm{l})$ by the glucose clamp technique. This induced a three- to fivefold greater insulin response to arginine. Compared to the response of diabetic subjects with similar hyperglycaemia, the control subjects secreted four to nine times more insulin. When the arginine stimulation was repeated $30 \mathrm{~min}$ later, no inhibition was observed, the second insulin
\end{abstract}

response being instead augmented 1.5- to 1.8 -fold. We conclude that (1) the insulin response to arginine is markedly reduced in Type 2 diabetes; (2) arginine-induced time-dependent inhibition of insulin release is abolished in patients with minimal to moderate hyperglycaemia; (3) this is probably due to the acute synergistic action of glucose and arginine on the B cell; (4) time-dependent inhibition of insulin release may be a protective mechanism against insulin oversecretion following repetitive stimulation of the pancreas; its abolition in hyperglycaemic states may be a compensatory mechanism, allowing substantial increases in insulin output.

Key words: Insulin release, islet refractory phase, glucose-arginine interaction, Type 2 diabetes, glucose clamp.
Previous studies in vivo and in vitro have demonstrated that the response of the pancreas to insulin secretagogues may be modified by prior exposure to the stimulator. Prolonged stimulation with glucose, repeated after a rest interval, resulted in two- to threefold amplification of the second insulin response [1-9]. In contrast, when glucose was given as a short (bolus) stimulation, the insulin response to a subsequent challenge was reduced $[1,3,4,10]$. With arginine only the inhibitory component of this time-dependent effect could be demonstrated [3]. Thus insulin secretagogues, apart from their acute releasing effect, may generate a state in the islet which according to the nature of the stimulator and the conditions of exposure induce potentiation or inhibition of the response to subsequent stimulations.

The effect of arginine on insulin secretion is glucose-dependent, the amino acid being ineffective at low glucose levels [11]. In addition, a strong synergism exists between arginine and high concentrations of glucose with respect to the stimulation of the acute insulin response [12]. These facts prompted us to study the timedependent inhibitory (TDI) effect of repetitive arginine stimulations under conditions where the glucose-arginine synergism is expected, i.e. in subjects with various degrees of hyperglycaemia, to clarify if these two sets of events in the islet are interrelated.

\section{Materials and methods}

\section{Subjects}

Seven healthy volunteers (21-31 years, within $10 \%$ of ideal body weight) participated. Five Type 2 (non-insulin-dependent) diabetic patients (41-55 years) were taken off oral hypoglycaemic agents and other medication at least 7 days before the study. Their fasting plasma glucose ranged between $9.2-15.9 \mathrm{mmol} / 1$ on the day of study. The five healthy obese volunteers (19-50 years) had a body weight between 156 and $168 \%$ of ideal. The nature of the study was explained to all participants and written consent obtained.

Teflon catheters were inserted into antecubital veins of both arms and, at 0 and $30 \mathrm{~min}$, arginine hydrochloride $(75 \mathrm{mg} / \mathrm{kg})$, diluted in saline to a final concentration of $10 \%$, was rapidly injected IV. Blood samples were collected from the contralateral arm into heparinized tubes every $2 \mathrm{~min}$ for the following $20 \mathrm{~min}$. The plasma was immediately separated and its glucose concentration determined with a Beckman Glucose Analyzer I. Plasma for insulin determination was stored 


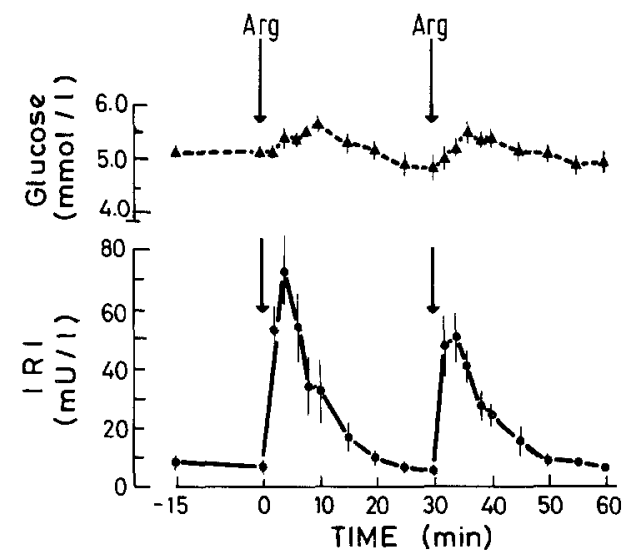

Fig. 1. Inhibition of immunoreactive insulin (IRI) secretion in normal man by consecutive injections of arginine $(75 \mathrm{mg} / \mathrm{kg}$, arrows) at a 30 min interval. Results are mean \pm SEM of seven subjects

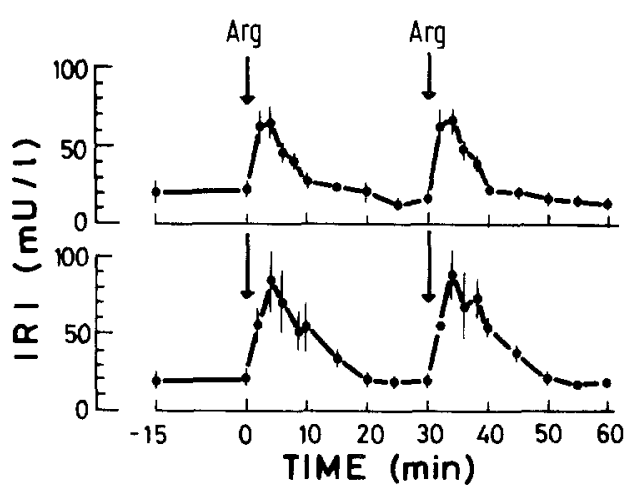

Fig. 2. Plasma immunoreactive insulin (IRI) levels following two consecutive injections of arginine ( $75 \mathrm{mg} / \mathrm{kg}$, arrows) at a $30 \mathrm{~min}$ interval in Type 2 diabetic (upper panel) and obese (lower panel) subjects. Results are mean \pm SEM of five subjects each

at $-20^{\circ} \mathrm{C}$. In the hyperglycaemic glucose clamp experiments, glucose $(150 \mathrm{mg} / \mathrm{kg})$ was injected IV followed by the infusion of a $15 \%$ glucose solution at rates adjusted to maintain a constant plasma glucose level.

\section{Analytical procedures}

Insulin (IRI) was determined by radioimmunoassay with guinea pig anti-(porcine) insulin serum (Linco Research, Eureka, Missouri, USA) and human insulin standard (Novo Research Institute, Bagsvaerd, Denmark). Statistical analyses were performed using twotailed paired Student's t-test. Results are expressed as mean \pm SEM. The term integrated IRI relates to the sum of incremental insulin concentrations in the samples indicated.

\section{Results}

In healthy subjects, when arginine was injected twice at a 30-min interval, two sharp peaks of insulin response were seen, the second being $20 \%$ smaller (Fig. 1). Although the dose of arginine in the present study was relatively small [for comparison 3,13 ], both the 30 -min integrated insulin levels and the peak hormone level were

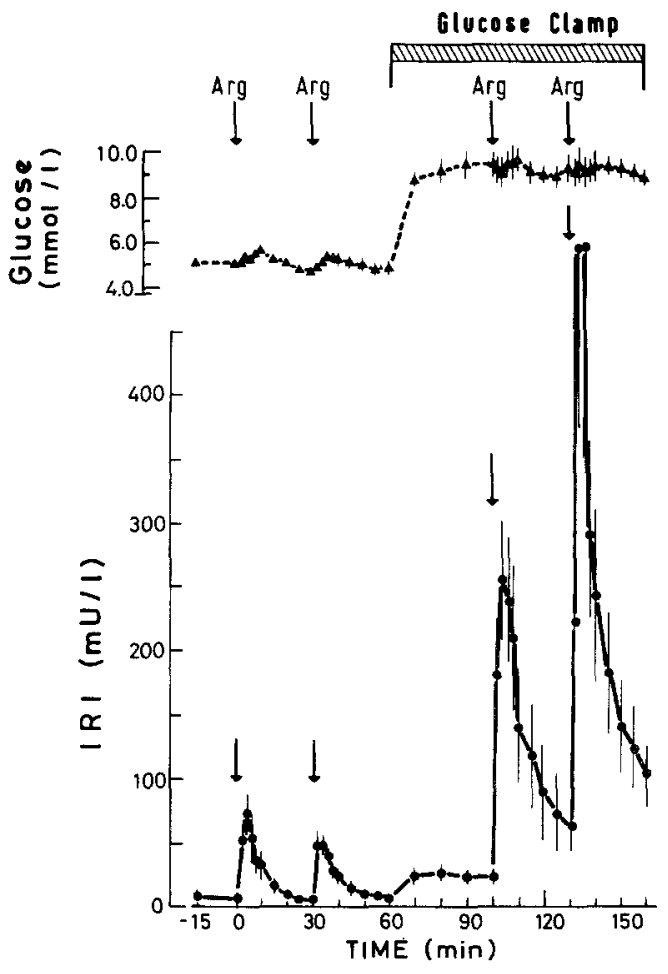

Fig.3. Abolition of the inhibitory effect of repeated arginine stimulations by mild hyperglycaemia in normal man. Arginine $(75 \mathrm{mg} / \mathrm{kg}$, arrows) was administered first during basal conditions, then during $100 \mathrm{~min}$ of mild hyperglycaemia (glucose clamp). Results are mean \pm SEM of seven subjects. IRI $=$ Immunoreactive insulin

consistently reduced following the second arginine injection (Table 1). Plasma glucose fluctuated not more than $10 \%$ after each injection (Fig. 1).

When the same experimental protocol was applied to Type 2 diabetic patients and obese subjects, no arginine-mediated inhibition of insulin secretion could be demonstrated (Fig. 2). On the contrary, both integrated and peak insulin levels were somewhat higher after the second stimulus (Table 1).

The latter two groups had fasting hyperglycaemia $(6.3 \pm 0.2 \mathrm{mmol} / 1$ in the obese subjects and $12.7 \pm$ $1.6 \mathrm{mmol} / 1$ in Type 2 diabetic patients versus $5.2 \pm$ $0.2 \mathrm{mmol} / 1$ in control subjects). To investigate whether mild hyperglycaemia per se abolished the arginine-induced TDI, plasma glucose in healthy volunteers was elevated to $9.3 \pm 0.3 \mathrm{mmol} / 1$ by the glucose clamp technique. This degree of hyperglycaemia led to strong amplification of the insulin response to arginine, a 5.3-fold increase in the integrated IRI, and a threefold increase in peak insulin response being observed at the first injection (Fig. 3 and Table 1). The inhibition of insulin release observed when arginine was given at basal glucose was completely abolished by the hyperglycaemia: instead of the expected $20 \%$ inhibition, the integrated IRI to the second arginine injection was augmented 1.5 -fold and the peak response 1.8 -fold during the glucose clamp (Table 1). 
Table 1. Insulin response to repeated arginine injections

\begin{tabular}{|c|c|c|c|c|c|c|c|c|}
\hline \multirow[b]{2}{*}{ Arginine injection } & \multicolumn{4}{|c|}{$\begin{array}{l}\text { Integrated IRI } \\
\left(\mathrm{mU} \cdot \mathbf{1}^{-1} \cdot 30 \mathrm{~min}^{-1}\right)\end{array}$} & \multicolumn{4}{|l|}{$\begin{array}{l}\text { Peak IRI } \\
(\mathrm{mU} / \mathrm{l})\end{array}$} \\
\hline & 1 & 2 & $\begin{array}{l}\text { Ratio } \\
2: 1\end{array}$ & $p$ & 1 & 2 & $\begin{array}{l}\text { Ratio } \\
2: 1\end{array}$ & $p$ \\
\hline Control subjects $(n=7)$ & $225 \pm 69$ & $169 \pm 40$ & 0.79 & $<0.025$ & $65 \pm 15$ & $52 \pm 8$ & 0.80 & $<0.05$ \\
\hline Control subjects clamped $(n=7)$ & $1182 \pm 315$ & $1770 \pm 400$ & 1.50 & $<0.01$ & $193 \pm 36$ & $354 \pm 74$ & 1.83 & $<0.01$ \\
\hline Type 2 diabetic patients $(n=5)$ & $136 \pm 10$ & $180 \pm 20$ & 1.32 & $<0.05$ & $51 \pm 8$ & $56 \pm 7$ & 1.10 & NS \\
\hline
\end{tabular}

Results expressed as mean $\pm \mathrm{SEM} ; \mathrm{NS}=$ not significant

\section{Discussion}

Many insulin secretagogues modify the B cell so as to augment or diminish its responsiveness to subsequent stimulations. Prior exposure of the islet to glucose for 20-60 min augmented markedly the insulin response to any other stimulus applied up to $60 \mathrm{~min}$ later [1-9, 14-16]. Blocking insulin secretion during the priming period had no effect on this potentiating memory $[3,8$, $14,16]$. When glucose was given to normal subjects as a bolus injection rather than a prolonged infusion, instead of potentiation a decrease of the insulin response to subsequent stimulation was observed $[3,4,10]$. The induction of this refractory state in the islet, or inhibitory memory, was observed also with arginine, whether given as rapid intravenous injection or prolonged infusion [3]. As in the case of the potentiating memory, suppression of the insulin response during the priming period did not abolish the appearance of the subsequent refractory state [3].

The dissociation of the effect of glucose or arginine on acute insulin release from that inducing time-dependent modulations made us assume that these two actions are mediated by different cellular mechanisms [4]. Accordingly, the time-dependent potentiating action of glucose was intact in mildly diabetic subjects [17] and in an animal model of non-insulin-dependent diabetes, the spiny mouse [18]. We therefore expected that the arginine-induced refractoriness (TDI) of the islet would be similar in normal and diabetic man. Our results clearly show that in Type 2 diabetic patients, as well as in obese subjects with minimal chronic hyperglycaemia, sequential stimulations with arginine did not show the expected TDI. When mild hyperglycaemia was maintained in healthy volunteers, we were able to show that abolition of TDI was not due to some basic modification of the diabetic islet, or to longstanding hyperglycaemia. In these studies not only was the inhibition of the second insulin response to arginine abolished, but the response was significantly amplified. A similar tendency, albeit less pronounced, was also observed in the patient group.

The nature of the arginine-induced TDI is unknown. However, the results clearly indicate that glucose may interfere with it. The functional role of TDI might be related to the temporal difference between the tight stimulus-secretion coupling in the $B$ cell on the one hand, and the time lag between insulin secretion and fall of blood glucose on the other hand. Unmodified B cell responses to repetitive stimulations might induce severe hypoglycaemia due to accumulation of insulin. Under hyperglycaemic conditions the risk of inducing hypoglycaemia by repetitive insulin discharges would be minimal.

The present study also emphasizes the quantitative aspect of the glucose-arginine synergism on insulin release, a fact often not appreciated. In normal man the effect of arginine on insulin release can be amplified fivefold or more by raising the plasma glucose to moderately hyperglycaemic levels (Table 1). This is important when evaluating the insulin secretory capacity of Type 2 diabetics. It is often said that the deficiency of the insulin response in these patients is specific for glucose, while agents like arginine are quite efficient $[19$, 20]. Figure 2 may seem to justify such a statement: the insulin response to arginine was only marginally reduced in our diabetic patients. However, in terms of B cell function, the fallacy of such observations becomes apparent if one compares the arginine-induced insulin response of the diabetics not to that of normoglycaemic control subjects but to that of volunteers rendered hyperglycaemic by the glucose clamp technique (Fig.3). Under such conditions, the controls responded to arginine with a ninefold greater integrated insulin response. Therefore it seems clear that, if evaluated correctly by reference to proper controls, the insulin deficiency of Type 2 diabetic patients is as great whether arginine or glucose is used as a stimulus.

Acknowledgments. The authors wish to thank M. Pick and G. Lebedeva for the insulin assays and L. Granot for assistance in manuscript preparation. This work was supported in part by Grant No. R01 AM 21598 from the National Institutes of Health, a grant from the Juvenile Diabetes Foundation, and a grant from the Israel Ministry of Health, Chief Scientist's Office.

\section{References}

1. Cerasi E, Fick G, Rudemo M (1974) A mathematical model for the glucose induced insulin release in man. Europ J Clin Invest 4: $267-278$ 
2. Cerasi E (1975) Potentiation of insulin release by glucose in man. I. Quantitative analysis of the enhancement of glucose-induced insulin secretion by pretreatment with glucose in normal subjects. Acta Endocrinol (Copenh) 79: 483-501

3. Efendic S, Lins PE, Cerasi E (1979) Potentiation and inhibition of insulin release in man following priming with glucose and with arginine - effect of somatostatin. Acta Endocrinol (Copenh) 90: $259-271$

4. Cerasi E (1981) Differential action of glucose on insulin release: Reevaluation of a mathematical model. In: Cobelli C, Bergman RN (eds) Carbohydrate metabolism. John Willey, New York, pp 3-24

5. Curry DL, Bennett LL, Grodsky GM (1968) Dynamics of insulin secretion by the perfused rat pancreas. Endocrinology 83 : $572-584$

6. Grodsky GM (1972) A threshold distribution hypothesis for packet storage of insulin and its mathematical modeling. J Clin Invest 51: 2057-2059

7. O'Connor MDL, Landahl H, Grodsky GM (1980) Comparison of storage and signal limited model of pancreatic insulin secretion. Am J Physiol 238: R378-R389

8. Grill V, Adamson U, Cerasi E (1978) Immediate and time-dependent effects of glucose on insulin release from rat pancreatic tissue. Evidence for different mechanisms of action. J Clin Invest 61 : 1034-1043

9. Ashby JP, Shirling D (1980) Evidence for priming and inhibitory effects of glucose on insulin secretion from isolated islets of Langerhans. Diabetologia 18: 417-421

10. Cerasi E (1975) Feedback inhibition of insulin secretion in subjects with high and low insulin response to glucose. Diabete Metab 1: 73-76

11. Efendic S, Cerasi E, Luft R (1971) Role of glucose in arginine-induced insulin release in man. Metabolism 20:568-579

12. Efendic S, Cerasi E, Luft R (1974) Quantitative study on the potentiating effect of arginine on glucose-induced insulin response in healthy, prediabetic and diabetic subjects. Diabetes 23:161-171
13. Assan R, Efendic S, Luft R, Cerasi E (1981) Dose-kinetics of pancreatic glucagon responses to arginine and glucose in subjects with normal and impaired pancreatic B cell function. Diabetologia 21 : $452-459$

14. Grill V, Adamson U, Rundfeldt M, Andersson S, Cerasi E (1979) Glucose memory of pancreatic B and A cells: evidence for common time dependent actions of glucose on insulin and glucagon secretion in the perfused rat pancreas. J Clin Invest 64: 700-707

15. Grill V (1981) Time and dose dependencies for priming effect of glucose on insulin secretion. Am J Physiol 240: E24-E31

16. Cerasi E (1975) Potentiation of insulin release by glucose in man. II. Role of the insulin response and enhancement of stimuli other than glucose. Acta Endocrinol (Copenh) 79:502-510

17. Cerasi E (1975) Potentiation of insulin release by glucose in man. III. Normal recognition of glucose as a potentiator in subjects with low insulin response and in mild diabetes. Acta Endocrinol (Copenh) 79:511-534

18. Nesher R, Cerasi E (1981) Repeated glucose stimulation corrects the diabetic type insulin secretion from perifused acomys islets. Diabetologia 21: 308 (Abstract)

19. Floyd JC, Fajans SS, Conn JW, Triffault C, Knopf RF, Guntsche E (1968) Secretion of insulin induced by amino acid and glucose in diabetes mellitus. J Clin Endocrinol Metab 28: 266-276

20. Kipnis DM (1968) Insulin secretion in diabetes mellitus. Ann Intern Med 69: 891-901

Received: 17 February 1983

and in revised form: 5 September 1983

Dr. Rafael Nesher

Department of Endocrinology and Metabolism

Hadassah Medical Center

P.O. Box 12000

Jerusalem, Israel 